\title{
ReMed: Unterstützung in persönlichen Krisen
}

\author{
Das Unterstützungsnetzwerk ReMed berät und begleitet Ärztinnen und Ärzte in \\ kritischen Momenten - zum Beispiel dann, wenn sich eine persönliche Krise auf den \\ Berufsalltag auszuwirken droht.
}

Jürg Beutler

Kommunikation FMH

\section{Erfahrungsbericht}

Ein 59-jähriger Hausarzt mit einer Gruppenpraxis in einer kleineren Stadt und Vater von zwei erwachsenen Kindern berichtet von seiner Depression:

Es war ein harter Schlag: Nach 22 Jahren Ehe teilte mir meine Frau mit, dass sie einen anderen Mann liebe und sich trennen wolle. Ich stürzte in eine tiefe Krise. Natürlich, mein Beruf nahm in meinem Leben viel Platz in Anspruch - aber meine Frau hatte ja auch ihren eigenen Bereich. Lange Zeit hat das für uns gestimmt, jetzt plötzlich nicht mehr.

Rückblickend weiss ich, dass wir uns entfremdet hatten. Meine Frau warf mir vor, dass ich nach ihrem

ReMed meldet sich bei jeder Kontaktaufnahme innerhalb von 72 Stunden und bespricht unverbindlich und vertraulich die persönliche Situation und individuelle Handlungsmöglichkeiten. ReMed ist an das Arztgeheimnis gebunden. Benötigen Sie Unterstützung? Oder eine Ärztin, ein Arzt aus Ihrem Umfeld?

Dann kontaktieren Sie ReMed:

24-Stunden-Hotline: 08000 73633,

info@swiss-remed.ch, www.swiss-remed.ch schweren Verkehrsunfall nicht für sie da war - das stimmt wohl, aber ich habe es damals nicht realisiert. Schmerzhaft war vor allem die Reaktion unserer Kinder. Wochenlang haben sie uns vorwurfsvoll angeschwiegen, und sie verstehen uns auch heute noch nicht. Dies, obwohl wir als Eltern gut funktioniert haben übrigens auch heute noch. Die Situation war unerträglich: Ich bin so rasch wie möglich ausgezogen und habe mich scheiden lassen.

Wie ich den Weg aus der Krise gefunden habe? Ich hatte zum Glück keine Berührungsängste zur Psychiatrie. Schon früher hatte ich - bei leichteren depressiven Verstimmungen - professionelle Hilfe in Anspruch genommen. So habe ich mich auch jetzt bei dem Facharzt gemeldet, der mich bereits kannte. Und ich habe auch meine Praxiskollegin sofort informiert. Sie haben mich unterstützt, ohne sich einzumischen was sehr hilfreich war. Wichtigen Halt gaben mir auch meine Freunde und die klare Tagesstruktur in meinem Beruf.

Auf diesem Weg habe ich meine existentielle Krise gemeistert, ohne dass meine Arbeit als Hausarzt dar- unter gelitten hat. Ich kann anderen betroffenen Kollegen nur raten, sich in solchen Situationen rasch professionelle Hilfe zu suchen. Heute können sie sich ja auch an ReMed wenden.

\section{Interview mit dem Psychiater Peter Birchler}

Peter Birchler, Sie gehören dem Leitungsausschuss von ReMed an und haben als Psychiater direkten Kontakt zu Betroffenen. Ist es für Sie eine besondere Situation, wenn eine Ärztin oder ein Arzt bei Ihnen als Patient in der Praxis sitzt?

Die Situation ist insofern besonders, weil ich den Patienten auch von seiner beruflichen Seite wahrnehmen will. Ich begegne in der Praxis einem Patienten und einem Kollegen, der sich in einer Notlage, in einer Krise befindet. Er will gehört und unterstützt werden. Das gemeinsame Erarbeiten eines Behandlungsziels beinhaltet in der Regel auch die beruflichen Kompetenzen und Erfahrungen. Ich versuche zum Beispiel aufzuzeigen, dass persönliche Schwierigkeiten nicht a priori mit fachlicher Inkompetenz gleichzusetzen sind. Der gemeinsame berufliche Hintergrund kann dabei den Aufbau einer vertrauensvollen therapeutischen Beziehung fördern. Ganz wichtig ist auch der Hinweis, dass die strikte Einhaltung der ärztlichen Schweigepflicht natürlich auch gegenüber Kollegen gilt.

Denken Sie, dass es für Ärzte noch schwieriger ist, Hilfe in Anspruch zu nehmen?

Aus meiner Erfahrung schon. Wir Ärzte glauben immer noch, dass wir Krisen eigenständig meistern müssen, dass wir letztlich gar keine «echten» Probleme haben. Die Inanspruchnahme von Hilfe ist für viele von uns immer noch Ausdruck von Versagen - anstatt von Kompetenz und Verantwortungsbewusstsein. Ich erachte es als äusserst wichtig, dass Ärzte in ihrem zunehmend schwierigen beruflichen Umfeld dank ReMed kollegiales Verständnis und professionelle Unterstützung finden können.
Dr. med. Michael Peltenburg

Facharzt für Allgemeinmedizin FMH

michael.peltenburg@hin.ch

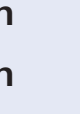

